\title{
The Vision of Challenges, a Unique Journal in an Era of Planetary Health Challenges
}

\author{
Susan L. Prescott 1,2,3,4,5 (D)
}

1 inVIVO Planetary Health, The Worldwide Universities Network (WUN), Baltimore, MD 21231, USA; susan.prescott@telethonkids.org.au

2 The ORIGINS Project, Telethon Kids Institute, Perth Children's Hospital, 15 Hospital Avenue, Nedlands, WA 6009, Australia

3 School of Medicine, University of Western Australia, Nedlands, WA 6009, Australia

4 The Institute for Integrative Health, 1407 Fleet St., Baltimore, MD 21231, USA

5 Department of Family and Community Medicine, University of Maryland School of Medicine, Baltimore, MD 21201, USA

Citation: Prescott, S.L. The Vision of Challenges, a Unique Journal in an Era of Planetary Health Challenges. Challenges 2021, 12, 14. https:// doi.org/10.3390/challe12010014

Received: 21 May 2021

Accepted: 21 May 2021

Published: 25 May 2021

Publisher's Note: MDPI stays neutral with regard to jurisdictional claims in published maps and institutional affiliations.

Copyright: (C) 2021 by the author. Licensee MDPI, Basel, Switzerland. This article is an open access article distributed under the terms and conditions of the Creative Commons Attribution (CC BY) license (https:// creativecommons.org/licenses/by/ $4.0 /)$.

\section{Introduction-Challenges in a Changing World}

The year 2020 will never be forgotten by the global community. An unseen virus, SARSCoV-2, wreaked havoc throughout our fragile planet. This crisis remains, and at the time of writing, over 3 million people have died from the coronavirus pandemic. At the same time, this catastrophe has unmasked many interconnected issues that had been hidden in plain sight for decades - a vast non-communicable disease quandary, a mental health crisis, systemic forms of injustice, discrimination, oppression, poverty, socioeconomic inequalities, and lack of equity, all of which have too often escaped discourse. These realities are, in turn, connected to wicked environmental challenges, including unfathomable biodiversity losses, climate change, environmental degradation, and resource depletion. As if that were not enough, we have an unprecedented, calculated spread of unhealthy products, ultra-processed foods, consumerism, and political polarization.

In short, the grand challenges of our time are interwoven in powerful ways. Thus, if we are to realistically find and evaluate solutions, it would seem obvious that a vigorous melding of transdisciplinary thought and research application would be an urgent necessity. It was under this notion that the journal Challenges was born.

In an era when there is a critical need to remove the lines of distinction between disciples, we need to create opportunities for specialists in all professions and research areas, to share and aim to integrate information with other disciplines. The Challenges journal is ideally positioned to magnify and accelerate this much-needed cross-sectoral discourse. Through our community and our activities, we hope to find new ways to ensure that recent events and ongoing challenges lead to new opportunities for innovation, growth and creativity towards novel solutions guided by mutualistic value systems.

\section{Extending the Vision and the Potential of Challenges}

Founding Editor-in-Chief, Prof. Dr. Andreas Manz, and my predecessor as Editorin-Chief, Dr. Palmiro Poltronieri, recognized the need for an international journal that could break down silos and provide a place for scholarly discourse across the physical sciences, health sciences, public health, ecology, anthropology, political/social/environmental sciences, philosophy, geography, spirituality, human culture, history/tradition, architecture/design, arts, ethics, and Indigenous governance and sciences. As a unique, international, scientific open-access journal, Challenges has published scholarly content, which is typically not publishable in traditional research journals-but this does not mean the path from submission to publication is without the rigors of peer-review.

The primary call for submissions to Challenges has not changed much since the inception of the journal. Viewpoint papers, case reports, research proposals (funded and 
unfunded), registered reports (study protocols before experiments being conducted), research plans (e.g., a protocol for a systematic review, further research of a technology application, etc.), research or technology ideas, policy studies relating to science and scholarly research, open contests aimed at solving grand challenges, prize announcements, description of prototypes, call for, or description of, international research collaborations or complementary support, etc., are all welcome.

What has changed is the requirement that individuals and/or groups submitting papers to Challenges, regardless of discipline, profession or perspective, should articulate the ways in which their submission is relevant to some (or preferably, many!) of the grand challenges of our time.

\section{Promoting Integration and Mutualism in an Age of Convergence}

"What might happen if biologists and other scholars so oriented were to combine talents even more than they do now, not simply to develop further their own special interests individually ... [they] ... are realizing more and more, their responsibility to society as well as to themselves."--Jonas E. Salk, 1962 [1]

It is our hope that Challenges will grow to facilitate collaborative vision and agendas that drive activity to link virtually every endeavor aimed at solving the interconnected challenges of our time-large and small alike. In keeping with Jonas Salk's concept of biophilosophy - investigating biological phenomena with input from academic disciplines that study human culture, tradition, arts and ethics—our journal is positioned to provide a leading example of an approach that will be essential in the 21st century [1-3]. As well as providing a platform to explore new technologies (which are generally fragmented, siloed and discipline-based), it will champion a call to action for more direct collaboration between biologists, humanists and scholars of all kinds [2].

The emergence of "Planetary Health" as a collective vision for science, medicine and all of society provides the clear imperative for this initiative. In 2015, the Rockefeller Foundation-Lancet Commission on Planetary Health concluded that health promotion needs to be viewed through a new, holistic lens: "the achievement of the highest attainable standard of health, wellbeing, and equity worldwide through judicious attention to the human systems - political, economic, and social - that shape the future of humanity and the Earth's natural systems that define the safe environmental limits within which humanity can flourish" $[4,5]$. This transition from public to planetary health is a professional acknowledgment that public health (the historical vanguard for social justice) cannot be restricted in its reach [6]; achieving the goals of public health is predicated on ecological justice and the stability of fragile planetary ecosystems that sustain all life [7].

The coming years will, therefore, see the need to apply the ambitious integrative approaches to our global health and environmental challenges. To position itself in a leading role with a voice in these global planetary agendas, Challenges must not only achieve excellence in niche areas but encourage all contributors to apply this knowledge and resources in a more integrative way (Figure 1). With an expansive leadership and vision facilitated through a growing number of collaborating planetary health networks, Challenges is well placed to contribute to this critical agenda. 

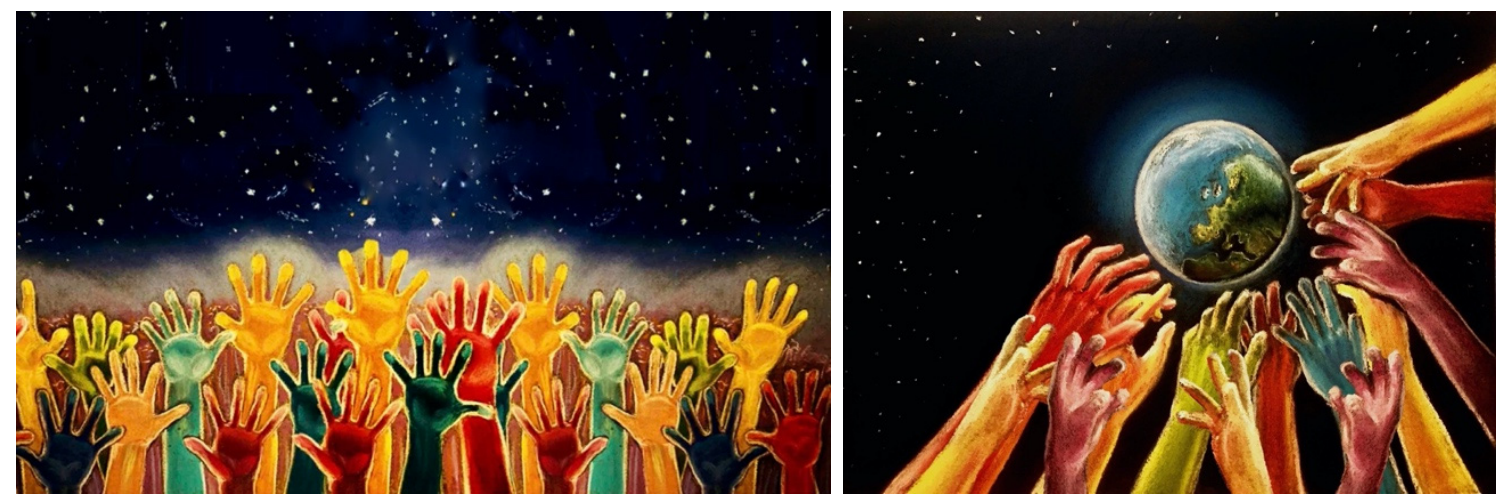

Figure 1. Encouraging diverse perspectives and discourse from across disciplines is essential to address the grand challenges of our time-where the work of all groups is made relevant to the wider issues, opening new opportunities to contribute to shared solutions.

\section{From Challenges May Come New and Accelerated Opportunities}

In so many ways, we are emerging from a year of "mass trauma" that has left the world in a literal state of "post-traumatic stress" affecting all systems at all scales, across the continuum of people, places and planet—essentially the many systems that are addressed through the broad scope of Challenges journal.

However, the other side of this coin is that after any trauma, there is the opportunity for "post-traumatic growth." Challenges or events that break the status quo can provide new or accelerated opportunities for change in all systems, which may not have been there before. Acute events can expose chronic problems that may not have been recognized or acknowledged, or that seemed impossible to overcome. Such events give new perspectives and greater awareness that can create new possibilities and galvanize action beyond merely recovering to a previous state or situation. This applies as much at collective scales as it does to personal growth.

In this way, the aftermath of this "mass trauma" can provide opportunities for largescale post-traumatic growth on a continuum towards flourishing. However, as with any growth, this needs to be nourished to reach its potential. Moreover, for this to occur, we need to encourage deeper reflection, and re-appraisal of values towards higher levels of environmental and social concern, greater self-awareness, and greater shared wisdom.

This poses the important questions of how we cultivate wisdom and how we cultivate ethics to have more mutualistic value systems as a compass as we address our challenges. We must consider how we define "progress" and "growth" in more meaningful ways and recognize that not all innovation is improvement. We must consider what true flourishing means across scales for all people, in all places, and our planet.

The Challenges journal is ideally positioned to magnify and accelerate this potential through much-needed cross-sectoral discourse. Through our community and our activities, we might hope to find new ways to ensure that recent events will lead to new awareness for growth at all scales-because change that once seemed impossible has now become essential.

\section{Conclusions}

The year 2020 has been filled with turmoil in which challenges seemed to greatly outweigh opportunities. However, this has prompted greater consideration of the unhealthy status quo and new ways to address this. As coincidence would have it, 2020 also happened to be the 10th anniversary of Challenges. It has been a time to reflect upon the unique purpose of the journal and express gratitude to many different experts who have allowed the journal to blossom from its seedling idea. While our core vision remains the same, it is easy to argue that the urgency of fulfilling it is even greater. Now is the time for 
hope and to search for even greater new opportunities hidden within our many challenges. We welcome contributions from all disciplines on all topics with these goals in mind.

Funding: This research received no external funding.

Conflicts of Interest: The author declares no conflict of interest.

\section{References}

1. Salk, J.E. Biology in the Future. Perspect. Biol. Med. 1962, 5, 423-431. [CrossRef] [PubMed]

2. Prescott, S.L.; Logan, A.C. Down to Earth: Planetary Health and Biophilosophy in the Symbiocene Epoch. Challenges 2017, 8, 19. [CrossRef]

3. Salk, J. The Survival of the Wisest; Harper and Row: New York, NY, USA, 1973; ISBN 0-06-013738-X.

4. Whitmee, S.; Haines, A.; Beyrer, C.; Boltz, F.; Capon, A.G.; Dias, B.F.D.S.; Ezeh, A.; Frumkin, H.; Gong, P.; Head, P.; et al. Safeguarding human health in the Anthropocene epoch: Report of The Rockefeller Foundation-Lancet Commission on planetary health. Lancet 2015, 386, 1973-2028. [CrossRef]

5. Craig, J.M.; Prescott, S.L. Planning ahead: The mental health value of natural environments. Lancet Planet. Health 2017, 1, e128-e129. [CrossRef]

6. Horton, R.; Beaglehole, R.; Bonita, R.; Raeburn, J.; McKee, M.; Wall, S. From public to planetary health: A manifesto. Lancet 2014, 383, 847. [CrossRef]

7. Prescott, S.L.; Logan, A.C. Transforming Life: A Broad View of the Developmental Origins of Health and Disease Concept from an Ecological Justice Perspective. Int. J. Environ. Res. Public Health 2016, 13, 1075. [CrossRef] [PubMed]

\section{Short Biography of Author}

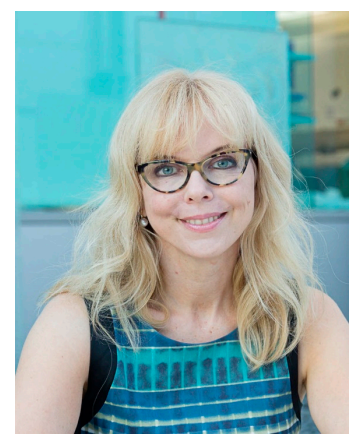

Prof. Susan L. Prescott MD, PhD, is a pediatrician and an immunologist, well known for her cuttingedge research into the early environmental determinants of health and disease. Her work also focuses on the interconnections between human health and planetary health and promoting mutualistic value systems for both ecological and social justice. She is Founding President of inVIVO Planetary Health, Editor-in-Chief of Challenges, and former President of the DOHaD Society (Developmental Origins of Health and Disease) of Australia and New Zealand, and a Director of the World Allergy Organization. She is also currently the Director of The ORIGINS project, an intervention birth cohort of 10,000 families aimed at improving lifelong physical and mental health. In addition to over 300 scientific publications, Susan is also an artist and award-winning author of several books. 